\title{
Alterations of signaling pathways in response to chemical perturbations used to measure mRNA decay rates in yeast
}

\author{
NICHOLE ESHLEMAN, XIANGXIA LUO, ANDREW CAPALDI, and J. ROSS BUCHAN
}

Department of Molecular and Cellular Biology, University of Arizona, Tucson, Arizona 85721, USA

\begin{abstract}
Assessing variations in mRNA stability typically involves inhibiting transcription either globally or in a gene-specific manner. Alternatively, mRNA pulse-labeling strategies offer a means to calculate mRNA stability without inhibiting transcription. However, key stress-responsive cell signaling pathways, which affect mRNA stability, may themselves be perturbed by the approaches used to measure mRNA stability, leading to artifactual results. Here, we have focused on common strategies to measure mRNA half-lives in yeast and determined that commonly used transcription inhibitors thiolutin and 1,10 phenanthroline inhibit TORC1 signaling, PKC signaling, and partially activate HOG signaling. Additionally, 4-thiouracil (4tU), a uracil analog used in mRNA pulse-labeling approaches, modestly induces P-bodies, mRNA-protein granules implicated in storage and decay of nontranslating mRNA. Thiolutin also induces P-bodies, whereas phenanthroline has no effect. Doxycycline, which controls "Tet On/Tet Off" regulatable promoters, shows no impact on the above signaling pathways or P-bodies. In summary, our data argues that broad-acting transcriptional inhibitors are problematic for determining mRNA half-life, particularly if studying the impacts of the TORC1, HOG, or PKC pathway on mRNA stability. Regulatable promoter systems are a preferred approach for individual mRNA half-life studies, with 4tU labeling representing a good approach to global mRNA half-life analysis, despite modestly inducing P-bodies.
\end{abstract}

Keywords: Hog1; P-bodies; PKC; TORC1; mRNA decay

\section{INTRODUCTION}

Exposure of cells to stress triggers compensatory changes in gene expression, of which changes in mRNA decay play a key role (Fan et al. 2002; Pérez-Ortín et al. 2007). Enhancing mRNA decay typically affords a more rapid means to reduce mRNA levels than transcriptional inhibition alone, and thus adjustments in both processes are often observed (García-Martínez et al. 2004; Molin et al. 2009). However, understanding how stress events are sensed and relayed mechanistically to alterations in mRNA stability remains poorly understood. Generally, stress-responsive signaling pathways are more closely studied for their effects on transcription and translation, though several are implicated in regulating mRNA decay in yeast and other species; these include the TORC1 pathway, HOG pathway, and PKC pathway.

The TORC1 (target of rapamycin complex) pathway, conserved throughout eukaryotes, regulates cell growth and metabolism in response to environmental and nutrient cues, particularly carbon and nitrogen availability (Barbet et al. 1996; Thomas and Hall 1997; Loewith and Hall 2011). Inhibition of TORC1 activity during diauxic shift

Corresponding author: rbuchan@email.arizona.edu

Article is online at http://www.rnajournal.org/cgi/doi/10.1261/rna. 072892.119. or treatment with rapamycin reduces levels of several reporter and endogenous mRNAs due to enhanced deadenylation or mRNA decapping (Albig and Decker 2001). Conversely, TORC1 inhibition stabilizes select stress-responsive genes (Talarek et al. 2013). Global analysis of yeast $m R N A$ half-lives reveals that rapamycin treatment increased the average mRNA half-life, though also facilitated faster decay of numerous transcripts, including all ribosomal protein mRNAs (Munchel et al. 2011). Finally, TORC1 can directly phosphorylate Dcp2 (mRNA decapping enzyme), which correlates with the destabilization of autophagy mRNAs in C. neoformans (Hu et al. 2015).

The HOG (high osmolarity glycerol) pathway is a stressactivated protein kinase pathway that helps yeast cells sense and adapt to various environmental stresses, particularly osmotic stress (Brewster and Gustin 2014). During mild osmotic stress, most yeast housekeeping genes exhibit decreased mRNA stability, whereas stress-responsive genes increase in mRNA stability (Molin et al. 2009; Romero-Santacreu et al. 2009). However, in hog14 strains, destabilization of housekeeping mRNAs was impaired

(C) 2020 Eshleman et al. This article is distributed exclusively by the RNA Society for the first 12 months after the full-issue publication date (see http://rnajournal.cshlp.org/site/misc/terms.xhtml). After 12 months, it is available under a Creative Commons License (Attribution-NonCommercial 4.0 International), as described at http:// creativecommons.org/licenses/by-nc/4.0/. 
(Molin et al. 2009; Romero-Santacreu et al. 2009), with one study also suggesting stabilization of stress-responsive mRNAs was inhibited (Molin et al. 2009). Ste20, a kinase activator of HOG signaling, phosphorylates Dcp2 in response to various stresses, slowing the decay of select ribosomal protein mRNAs (Yoon et al. 2010). In human cells, p38 (Hog1 ortholog) activity is a key regulator of AU-rich element (ARE)-containing cytokine mRNAs (Schoenberg and Maquat 2012). Finally, in C. neoformans, destabilization of ribosomal protein mRNAs during glucose starvation depends on Hog1 function (Banerjee et al. 2016). During and following osmotic stress, HOG signaling has been linked to assembly and disassembly of Pbodies in yeast (Brengues et al. 2005; Romero-Santacreu et al. 2009). P-bodies are cytoplasmic assemblies of nontranslating mRNA-protein complexes (mRNPs) that are implicated in regulation of mRNA repression and mRNA decay (Jain and Parker 2013). Thus, some effects of Hog1 on mRNA stability may also reflect altered P-body functions.

The PKC (protein kinase C) pathway in yeast is best studied for its role in sensing cell well integrity. Under nutrient poor growth conditions, absence or conditional inactivation of PKC signaling pathway proteins (Pkh1, Pkh2, and $\mathrm{Pkc1}$ ) impairs deadenylation and decay of various reporter and endogenous mRNAs, and causes synthetic growth defects in dhh14 null strains (Luo et al. 2011); Dhh1 is a Pbody localizing protein that enhances mRNA decapping and translation repression. Pkh1/2 and Pkc1 also aid stress-induced increases in P-bodies under nutrient-poor conditions, though not under nutritionally rich conditions (Luo et al. 2011). Cell wall stress also triggers P-body induction in a PKC signaling-dependent manner, and relocalization of mRNAs that normally accumulate under cell wall stress to P-bodies, suggestive of possible alterations in their stability (García et al. 2019). Finally, as with p38, several studies in human cells indicate PKC signaling regulates stability of ARE-containing cytokine mRNAs (Schoenberg and Maquat 2012).

In this work, we examine how various chemical perturbations used to measure mRNA decay rates in yeast affect stress-responsive signaling pathways. Specifically, we examine at standard concentrations the effects of two general transcription inhibitory molecules, 1,10 phenanthroline (phenanthroline) and thiolutin, doxycycline (which controls Tet off/Tet on promoter systems) and 4-thiouracil (4tU), which is used in RNA pulse-labeling approaches. All approaches are commonly used to assess individual and global mRNA decay rates in yeast (Parker et al. 1991; Hughes et al. 2000; Grigull et al. 2004; Coller 2008; Munchel et al. 2011; Pérez-Ortín et al. 2013; Wada et al. 2017; Chan et al. 2018), and yet often lead to highly divergent results. Our western blot and microscopy findings suggest part of the reason for this may be aberrant activation or inhibition of signaling pathways that regulate
mRNA decay, particularly when using phenanthroline or thiolutin.

\section{RESULTS AND DISCUSSION}

\section{Phenanthroline and thiolutin impair TORC1 signaling via the Sch9 branch}

We first examined how 10 min of treatment with our transcription-regulating small molecules affected TORC1 signaling by examining Sch9 phosphorylation status in two common yeast strains (BY4741 and W303). Sch9 lies within one of two major downstream effector branches of the TORC1 signaling pathway (Fig. 1A; Loewith and Hall 2011; Hughes Hallett et al. 2014). Sch9 is directly phosphorylated by TORC1 under optimal growth conditions, but is rapidly dephosphorylated when TORC1 is inactivated, and thus is a commonly used indicator of TORC1 signaling activity. Rapamycin was used as a positive control of TORC 1 inactivation, and after 10 min of rapamycin treatment, Sch9 is indeed strongly dephosphorylated (Fig. 1B, lanes 1,2; Urban et al. 2007; Hughes Hallett et al. 2014).

Strikingly, phenanthroline and thiolutin inhibit TORC1 to the same extent as rapamycin (Fig. 1B, lanes 3,4,7,8). In contrast, doxycycline, $4 \mathrm{tU}$ and $\beta$-estradiol have no effect on Sch9 phosphorylation status (Fig. 1B, lanes 5,6,9,10, Fig. 1E). These effects were consistent between both yeast strain backgrounds and were not a result of solvents (ethanol or DMSO) used to dissolve the small molecules (Fig. 1C). These data suggested that phenanthroline and thiolutin are inhibitors of TORC1 signaling.

\section{Phenanthroline activates the PP2A TORC1 signaling branch}

We next looked at the PP2A-Tap42 branch of TORC1 signaling by looking at Par32 phosphorylation, a downstream target and indicator of PP2A-Tap42 branch signaling activity (Fig. 1A; Hughes Hallett et al. 2014; Boeckstaens et al. 2015).

As before, the effect of our molecules was examined after 10 min of treatment with rapamycin serving as a control for TORC1 inhibition (which activates PP2A-Tap42 signaling); as expected, clear Par32 phosphorylation was observed (Fig. 1D, lanes 1,2). Interestingly, phenanthroline, but not thiolutin, caused a similar shift after $10 \mathrm{~min}$ of treatment (Fig. 1D, lanes 3,4 vs. 7,8). None of the other small molecules significantly affected Par32 phosphorylation status. Thus, phenanthroline leads to activation of the PP2A TOR signaling branch, whereas thiolutin does not. Joint inhibition of Sch9 and PP2A signaling branches by thiolutin is reminiscent of AMPK/Snf1-mediated effects on TORC1 during glucose deprivation stress (Hughes Hallett et al. 2014). In summary, phenanthroline and thiolutin differentially affect PP2A-Tap42 signaling, suggesting a 
A

TORC1 signaling ON

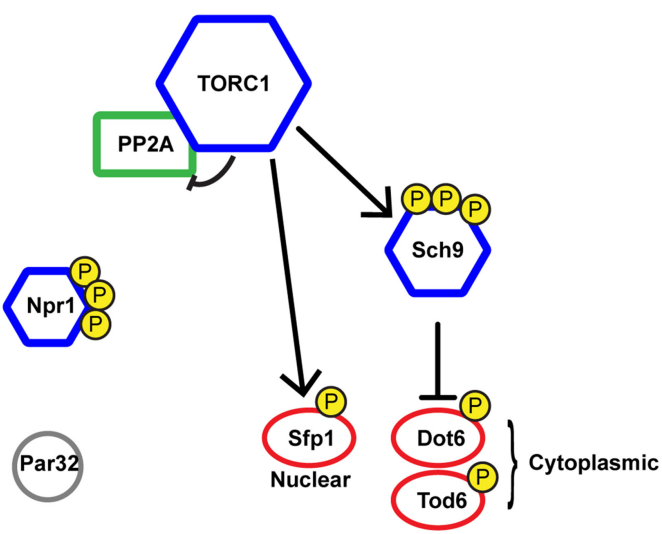

TORC1 signaling OFF

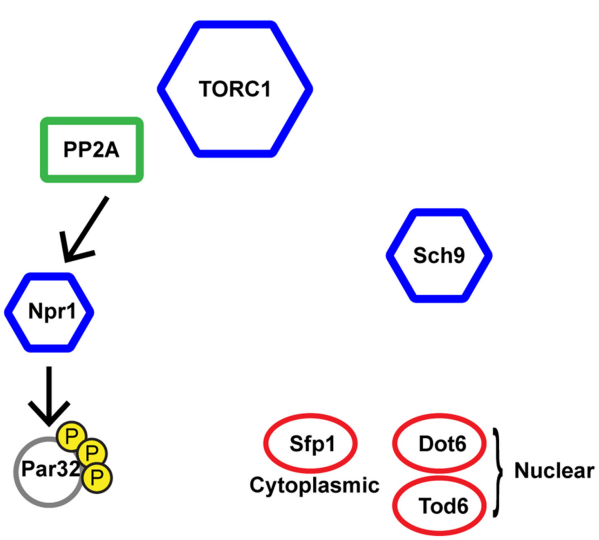

B

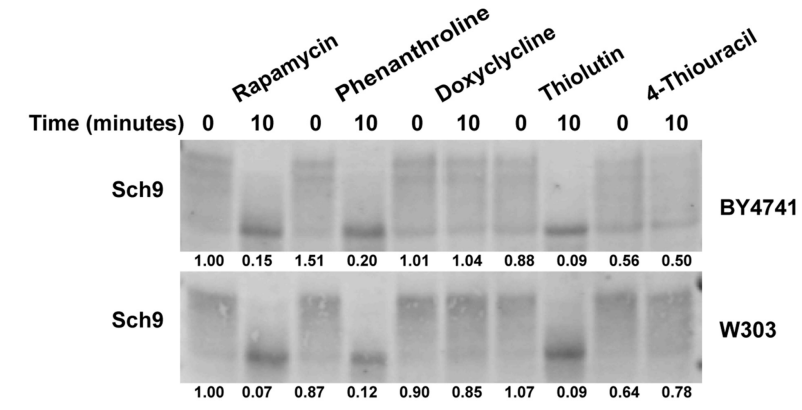

C
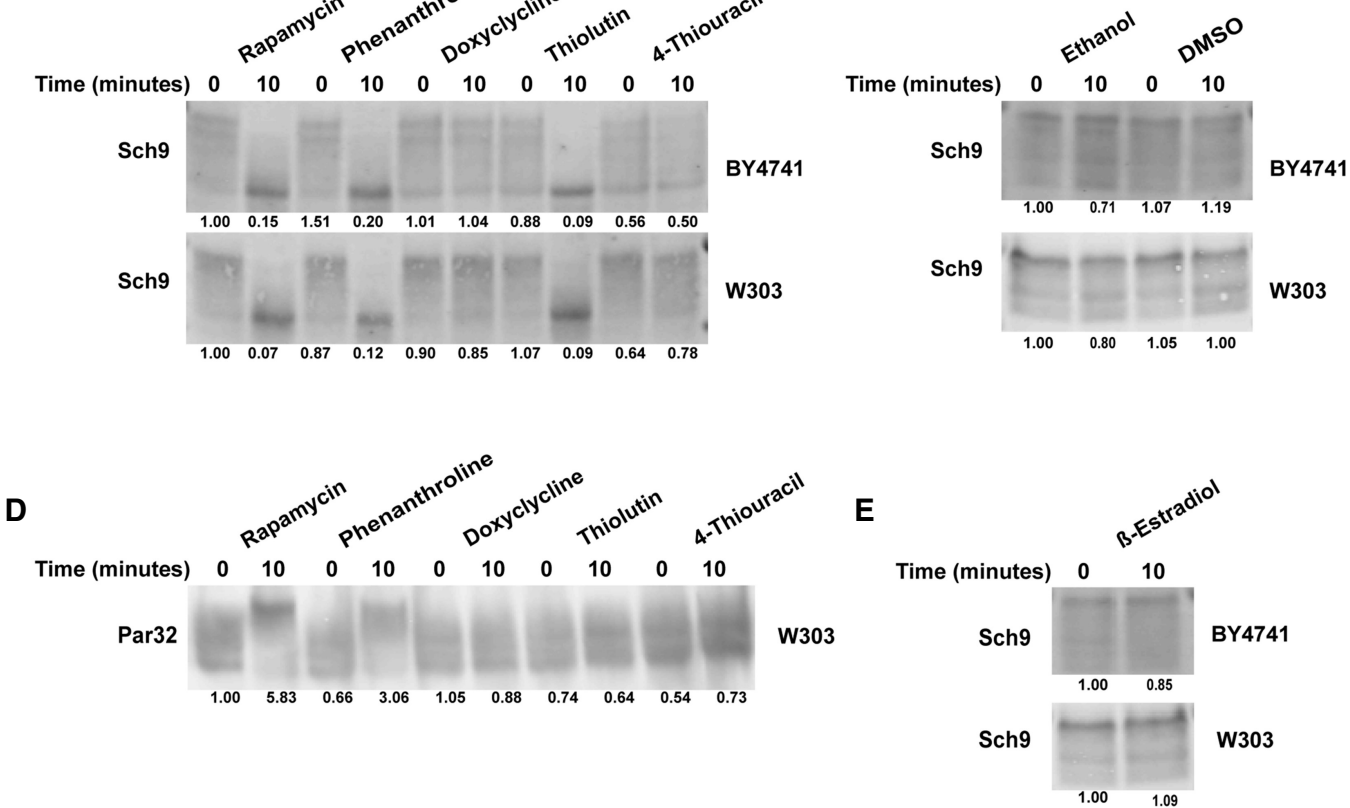

FIGURE 1. General transcriptional inhibitors impair TORC1 signaling. (A) Simplified model of TORC1 signaling, adapted from Hughes Hallett et al. (2014). (Blue hexagons) kinases, (green rectangle) phosphatase, (red circles) transcription factors, (gray circle) signaling effector. (B) Wildtype strains (BY4741 and W303) bearing HA-tagged Sch9 were grown to mid-log before a 0-min time point (i.e., no treatment) was harvested. Afterwards, indicated small molecules were added and yeast cultured for an additional 10 min before harvesting; additional processing details in Materials and Methods. Rapamycin serves as a positive control for TORC1 signaling inactivation. Image representative of two biological replicates. (C) Same as B, but solvents indicated were tested. (D) W303 bearing Myc-tagged Par32 was treated as in $B$. (E) As in $B$, with $\beta$-estradiol. Image representative of two biological replicates.

different mode of action of these molecules on TORC1 signaling.

\section{Dot6 and Sfp1 transcription factors relocalize in the presence of thiolutin and phenanthroline, consistent with TORC1 signaling inhibition}

We next assessed the effect of a 10 min treatment with our small molecules on the localization of transcription factors
Sfp1 and Dot6, whose nuclear or cytoplasmic localization is indicative of TORC1 signaling (Fig. 1A). Under optimal growth conditions, the transcription factor Sfp1 is directly phosphorylated by TORC1 and is localized in the nucleus where it facilitates ribosomal protein (RP) and ribosome biogenesis (Ribi) gene transcription (Lempiäinen et al. 2009). Conversely, cytoplasmic localization of RP/Ribi inhibitory transcription factors Dot6 and Tod6 is induced by Sch9 dependent phosphorylation. TORC1 inactivation, 
A

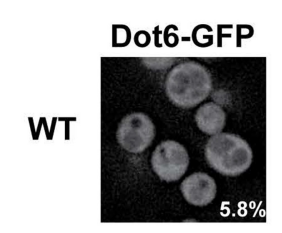

Rapamycin

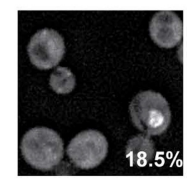

Phenanthroline

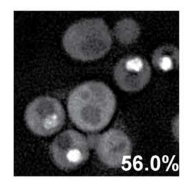

Doxycycline

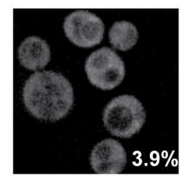

Thiolutin

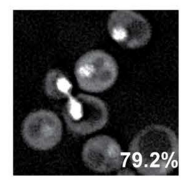

4-Thiouracil

D

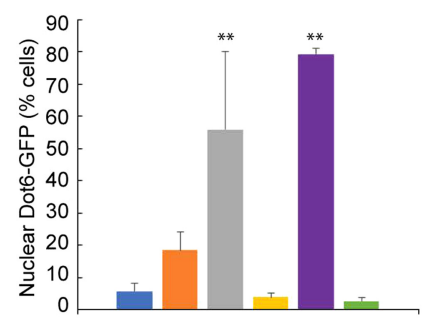

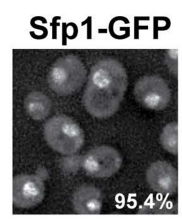
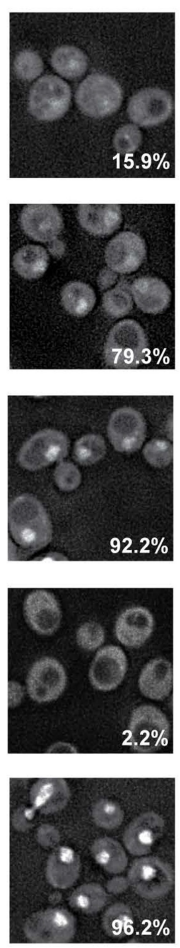

E

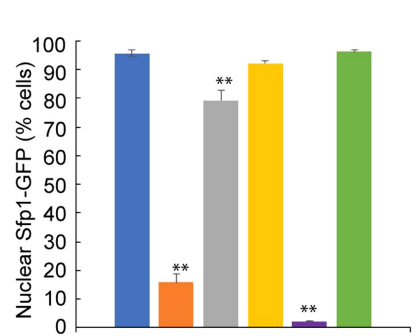

C
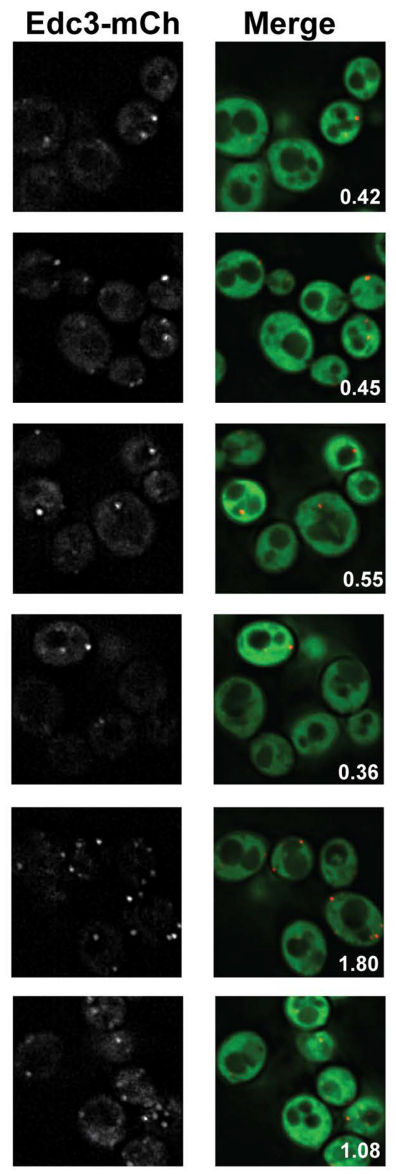

F

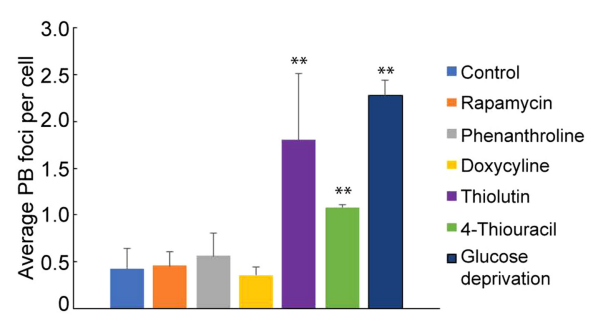

FIGURE 2. Effect of transcription small molecule regulators on P-bodies and Dot6 and Sfp1 localization. (A) WT BY47471 DOT6-GFP strains were examined in complete SD media \pm incubation with indicated molecules for $10 \mathrm{~min}$. Numbers indicate \% of cells with nuclear localization. Data representative of three biological replicates. (B) As in A but for BY4741 SFP1-GFP strains; data representative of two biological replicates. (C) BY4741 WT yeast transformed with pRB1 plasmid bearing Edc3-mCh (P-body marker) and Pab1-GFP (stress granule marker) proteins were examined in selective SD media (-Ura) with 10 min small molecule incubation. Edc3-mCh foci shown alone to reveal P-body induction differences; merged image indicates localization of P-bodies in cells. Numbers indicate average P-body foci/cell. Data representative of a $\geq 3$ biological replicates. (D) Quantification of $A$. (E) Quantification of B. $(F)$ Quantification of $C$; additional P-body quantification in Supplemental Table 2. Significance in $D-F$, relative to control, assessed by one-way ANOVA with Dunnett's post-hoc test. $\left.{ }^{* *}\right) P<0.01$.

and the resulting dephosphorylation of Sfp1, Dot6, and Tod6 reverses these localization phenotypes (Fig. 1A), causing Dot6 and Tod6-mediated transcriptional silencing of RP/Ribi genes (Huber et al. 2011).

As anticipated, Dot6 was strongly localized in the cytoplasm in our no-treatment control cells, with $<6 \%$ of cells exhibiting nuclear-localized Dot6. Rapamycin, serving as a TOR-inactivating control, caused $19 \%$ of cells to display clear Dot6 nuclear localization within $10 \mathrm{~min}$ (Fig. 2A,D). Both phenanthroline (56\%) and thiolutin (79\%) induced more striking nuclear localization of Dot6 than rapamycin over the same time period (Fig. 2A,D); we hypothesize that additional inhibitory effects of thiolutin and phenanthroline on PKA signaling, which like TORC1 also promotes 
cytoplasmic localization of Dot6 and Tod6 (Lippman and Broach 2009; Huber et al. 2011), may explain this result. In contrast, doxycycline and $4 \mathrm{tU}$ resembled control cells.

With Sfp1 localization, control, doxycycline and 4tU treated cells all showed $>92 \%$ nuclear localization (Fig. 2B,E). Interestingly, whereas rapamycin and particularly thiolutin both caused strong cytoplasmic relocalization of Sfp1 (16\% and 2\% nuclear localization), phenanthroline treatment maintained $79 \%$ of cells with nuclear enrichment, albeit the intensity of Sfp1 nuclear signal was generally reduced compared to control cells (Fig. 2B). Inhibition of PKA signaling also promotes Sfp1 cytoplasmic relocalization (Jorgensen et al. 2004; Marion et al. 2004). Thus, if phenanthroline and thiolutin do in fact inhibit PKA signaling (as hypothesized above), an additional variable must explain the poorer phenanthroline-induced Sfp1 cytoplasmic relocalization relative to thiolutin and rapamycin.

In summary, despite thiolutin and phenanthroline exhibiting similar transcription repression effects in yeast (Grigull et al. 2004), there is a nuance to their effects. Thiolutin caused the strongest relocalization of Dot6 and Sfp1 to and from the nucleus, respectively, with phenanthroline also exhibiting a strong nuclear relocalization effect on Dot6 relocalization (more potent than rapamycin). Conversely, rapamycin exhibits a more notable effect on Sfp1 relocalization than phenanthroline. These results are consistent with both thiolutin and phenanthroline impairing TORC1 and PKA signaling, but hint that thiolutin may have a more severe inhibitory effect on RP/Ribi gene transcription.

\section{P-bodies are induced by thiolutin and 4-thiouracil}

We next examined how a 10 min treatment with our small molecules affected P-body and stress granule assembly (Buchan 2014). P-bodies and stress granules increase in size and number when the translation is inhibited, owing to a higher proportion of nontranslating mRNAs with which to nucleate them. P-bodies are present at low levels in yeast under normal growth conditions, whereas stress granules typically only form during stress.

In control cells, a modest amount of P-bodies was observed as expected ( 0.42 foci/cell), whereas thiolutin significantly induced P-bodies (1.80 foci/cell; Fig. 2C,F; Supplemental Table 2). 4tU, despite showing no evidence of impairing stress signaling pathways, also caused a modest but significant increase in P-body number (1.08 foci/ cell). The dose tested here $(0.2 \mathrm{mM})$ was used in prior labeling analyses (Munchel et al. 2011), and is fivefold lower than recent work (Chan et al. 2018). This compares to an average of 2.28 P-bodies/cell in cells subject to glucose deprivation, which served as a positive control of P-body induction (Fig. 2F and data not shown). Phenanthroline, rapamycin, and doxycycline did not induce P-bodies. Stress granule induction was not seen in any of our treat- ment conditions, except for glucose deprived cells, and in a tiny fraction $(<1 \%)$ of thiolutin-treated cells. In summary, P-bodies are induced by thiolutin and to a lesser but still significant degree by $4 \mathrm{t} U$.

\section{Phenanthroline and thiolutin induce HOG signaling}

We next examined how our transcription-modifying small molecules affected HOG signaling. Hog1 is a mitogenactivated protein kinase (MAPK), an ortholog of p38 and JNK in human cells, and drives yeast transcriptional responses to hyperosmotic stress (Fig. 3A; Brewster and Gustin 2014).

The effect of our small molecules on Hog1 was assessed using Hog1 and phopsho-Hog1 antibodies, to assess overall levels and activation status, respectively. Ten minutes of $\mathrm{KCl}$ stress, at a final concentration of $0.4 \mathrm{M}$, was used as a positive control of Hog1 activation; as expected, we observed the appearance of phosphorylated Hog1 under these conditions (Fig. 3B). Additionally, phenanthroline and thiolutin also induced Hog1 phosphorylation, albeit to a lower extent than $0.4 \mathrm{M} \mathrm{KCl}$ stress, which itself is a modest osmotic stress. No effects of any other small molecules examined on Hog1 levels or phosphorylation status were observed. In summary, phenanthroline and thiolutin both induce HOG signaling.

\section{Phenanthroline and thiolutin inhibit PKC signaling}

Our final focus was on PKC signaling, a MAP Kinase cascade pathway which in yeast senses and maintains cell wall integrity; however additional roles in processes such as autophagy, apoptosis, endocytosis, cytokinesis, and actin cytoskeleton regulation are also known (Heinisch and Rodicio 2018). Pkc1 activation ultimately leads to phosphorylation, activation and nuclear relocalization of Slt2 in yeast (Fig. 3C). Here, Slt2 phosphorylates various transcription factors involved in cell wall maintenance and other processes.

The effect of our small molecules on PKC signaling was assessed using an antibody recognizing phosphorylated Slt2; we were unable to identify an antibody capable of recognizing nonphosphorylated Slt2 but verified that our small molecules did not affect levels of GFP-tagged Slt2. GAPDH was also used as a loading control. As a positive control, $1 \mathrm{~h}$ of zymolase treatment was utilized to perturb cell wall integrity; a clear increase in phosphorylated Slt2 was observed over basal levels under normal growth (Fig. 3D). Interestingly, both phenanthroline and thiolutin reduced phosphorylated Slt2 levels, indicative of inhibition of PKC signaling. No effect on PKC signaling was observed with any other small molecules (Fig. 3D). In summary, phenanthroline and thiolutin both inhibit PKC signaling. The collective findings from our work are summarized in Figure 4. 
A

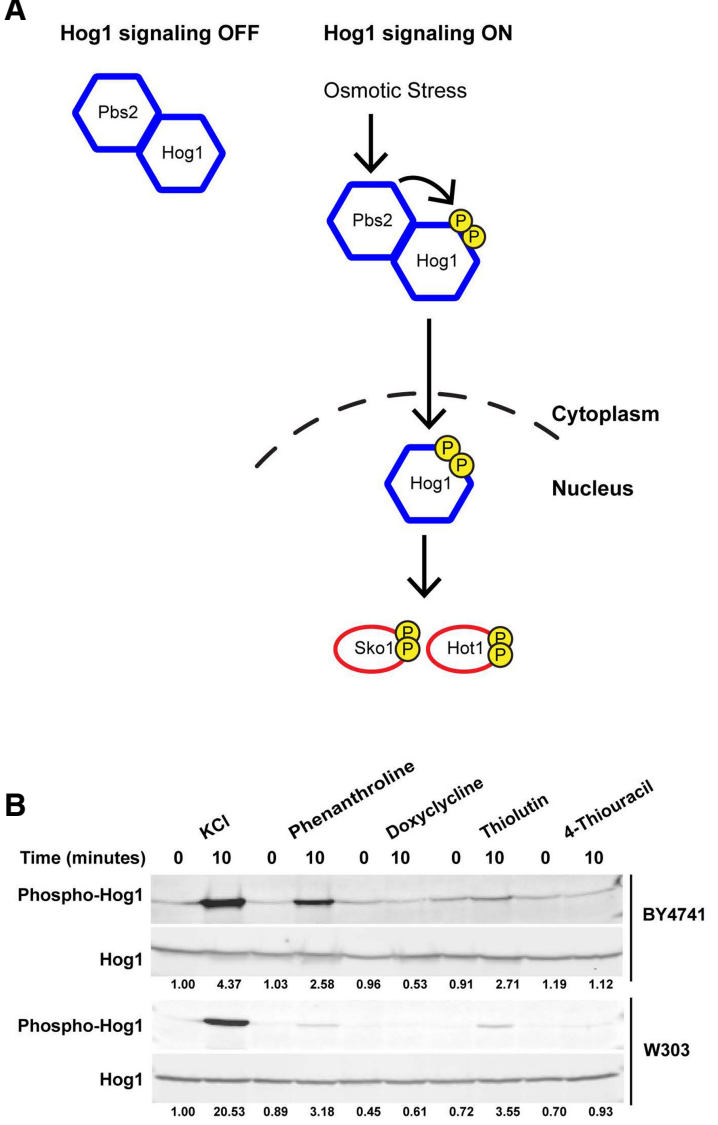

C

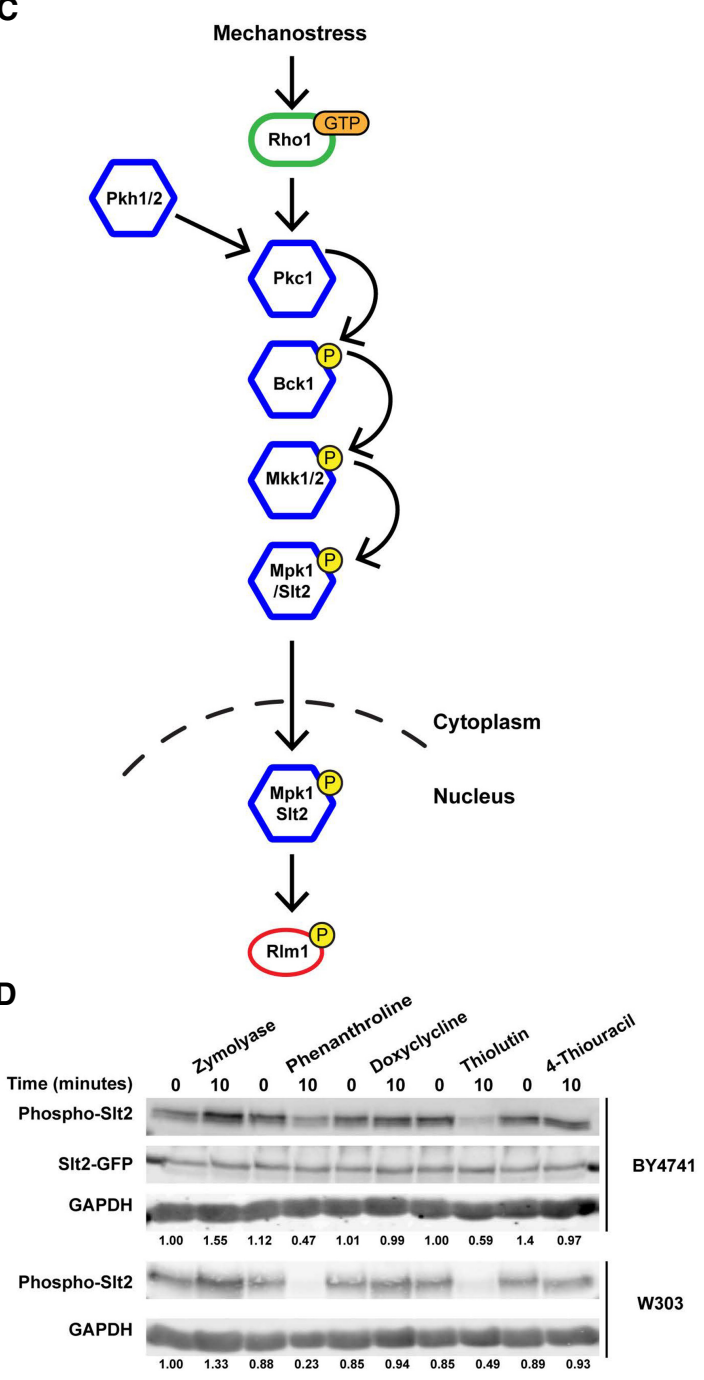

FIGURE 3. Phenanthroline and thiolutin induce HOG signaling and inhibit PKC signaling. (A) Simplified model of HOG signaling. Schematic designations as in Figure 1A. (B) Wild-type strains (BY4741 and W303) were grown to mid-log before a 0-min time point (i.e., no treatment) was harvested. Afterward, indicated small molecules were added and yeast cultured for an additional 10 min before harvesting; additional processing details in Materials and Methods. $\mathrm{KCl}$ serves as a positive control for Hog1 phosphorylation. (C) Simplified model of PKC signaling. Schematic designations as in Figure 1A. (D) Wild-type strains (BY4741 and W303) were grown to mid-log before a 0-min time point (i.e., no treatment) was harvested. Afterward, indicated small molecules were added and yeast cultured for an additional 10 min before harvesting; additional processing details in Materials and Methods. Zymolase (1 h) serves as a positive control for Slt2 phosphorylation/activation of PKC signaling. All western images representative of two biological replicates.

\section{Summary}

Given the perturbing effects of thiolutin and phenanthroline on all signaling pathways assessed, and the potent induction of P-bodies caused by thiolutin, we recommend that neither of these reagents be used to obtain mRNA half-life data. Note, a temperature-sensitive subunit (rpb1-1) of RNA Polymerase II (RNAPII) is also often used in yeast to measure mRNA decay in the absence of transcription (Nonet et al. 1987). However, the rpb1-1 mutation causes a global decrease in transcription rates of 2.7-fold, and a global increase in mRNA stability (a presumed adaptation mechanism) at $30^{\circ} \mathrm{C}$ (Sun et al. 2012).
Shifting to $37^{\circ} \mathrm{C}$ also induces heat-shock responses in yeast (Morano et al. 2012); hence we chose not to examine rpb1-1 yeast in our work and would suggest such a tool be used with caution.

Doxycycline and $4 \mathrm{tU}$ showed no effect on any of the stress signaling pathways examined. $\beta$-estradiol also had no effect on Sch9 phosphorylation status. Thus, should a yeast experimentalist's goal be the study of mRNA stability under differing stress conditions, our work suggests that regulatable promoters such as the Tet-off and $\beta$-estradiol promoter may represent good options. Finally, the modest induction of P-bodies by $4 \mathrm{t} \mathrm{U}$, and prior data on uracil analog effects on growth rate (Chan et al. 2018) and 
A

Hog1 signaling induced

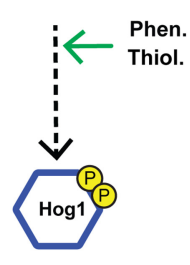

TORC1 signaling inhibited

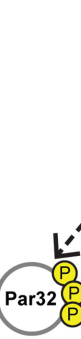

ToRe1 signaling inhibited

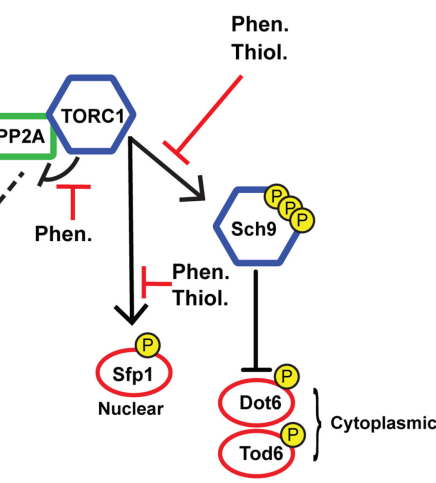

B
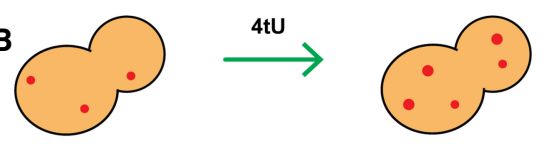

Modest P-body induction
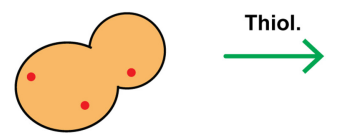

FIGURE 4. Summary diagram of results. (A) Phenanthroline (Phen.) and Thiolutin (Thiol.) both inhibit the TORC1 signaling pathways and activate the HOG and PKC pathways. The precise mechanism and point of inhibition/stimulation of indicated signaling pathways is not yet known. (B) Thiolutin and $4 \mathrm{tU}$ both induce P-bodies after $10 \mathrm{~min}$ of treatment.

rRNA processing (Burger et al. 2013) suggest that uracil analog incorporation can perturb RNA metabolic processes. To our knowledge, the effects of such incorporation on translation, secondary structure formation, and RNA modification, all of which may affect cytoplasmic mRNA regulation and thus mRNP granule assembly, remain unknown. A careful assessment of the effects on growth, and minimizing analog labeling concentrations and time periods is likely beneficial for the most accurate mRNA half-life data to be obtained, with the additional benefit that no promoter perturbations are required.

\section{MATERIALS AND METHODS}

\section{Yeast strains and growth conditions}

Untransformed yeast strains were cultured at $30^{\circ} \mathrm{C}$ with YPD medium. Strains transformed with plasmids were grown in SD medium with appropriate nutrients for plasmid selection. The transformation was performed by a standard LiAc method (Gietz and Woods 2006). The genetic background of strains used in this study are listed in Supplemental Table 1.

\section{Small molecule modifiers of transcription and TORC1 signaling}

The following molecules were incubated in yeast cultures for $10 \mathrm{~min}$ at the following concentrations. Rapamycin (TORC1 inhib-
PKC signaling inhibited

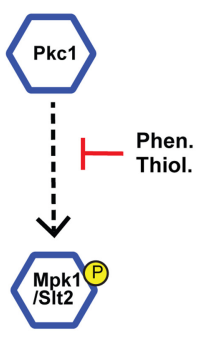

itor, $200 \mathrm{ng} / \mathrm{mL}$ - Fisher Scientific BP29631), dissolved in DMSO (Amresco 0231); 1,10 Phenanthroline (RNAP I-III inhibitor, $100 \mu \mathrm{g} / \mathrm{mL}$ - Sigma-Aldrich 131377), in ethanol (Fisher Scientific BP28184); doxycycline (Antibiotic/regulator of Tet-Off/On promoters; $10 \mu \mathrm{g} / \mathrm{mL}$ - Sigma-Aldrich D9891) in water, $\beta$-estradiol (regulator of $\beta$-estradiol promoter; $1 \mu \mathrm{M}$ - Sigma-Aldrich E8875), in ethanol; thiolutin (RNAP I-III inhibitor, $3 \mu \mathrm{g} / \mathrm{mL}$ - VWR 89157-260), in DMSO; 4tU (Uracil analog, $25 \mu \mathrm{g} / \mathrm{mL}$ Sigma-Aldrich 440736), in DMSO. All drug concentrations are based on standards in the field and/or the following studies (Grigull et al. 2004; Mnaimneh et al. 2004; Munchel et al. 2011). Ten minutes was chosen as a time period for analysis given that mRNA half-lives were recently reported to average 5 min (Chan et al. 2018), thus short-term effects are relevant for accurate half-life measurement.

\section{Band shift assays}

Sch9 and Par32 bandshift measurements were performed using a previously described protocol adapted from the Loewith laboratory (Urban et al. 2007; Hughes Hallett et al. 2014), with the following minor alterations. Forty-seven milliliters mid-log cultures harvested and incubated with $3 \mathrm{~mL}$ of $100 \%$ tricholoroacetic acid (TCA) were incubated on ice for between 30 min and $2 \mathrm{~h}$. During cleavage of carboxy-terminally HA-tagged Sch9 samples with 2-nitro-5-thiocyanatobenzoic acid (NTCB; aids separation of phospho-Sch9 fragments for gel analysis), incubation conditions were $12-16 \mathrm{~h}$ at $33^{\circ} \mathrm{C}$ in the dark (1 mM NTCB and 100 $\mathrm{mM}$ CHES, $\mathrm{pH}$ 10.5). Otherwise, all steps were as previously described (Hughes Hallett et al. 2014). HA (12CA5; Sigma-Aldrich, 11583816001) and C-Myc (Roche, M4439) antibodies were used for Sch9-HA and Par32-Myc detection, respectively (see Supplemental Table 1).

\section{Western blotting}

A $50 \mathrm{~mL}$ yeast culture was grown at $30^{\circ} \mathrm{C}$ in a shaking water bath until midlog $\left(\mathrm{OD}_{600} 0.5-0.6\right)$, split into $50 \mathrm{~mL}$ flasks with $5 \mathrm{~mL}$ of culture aliquoted to each, and treated for $10 \mathrm{~min}$ (at $30^{\circ} \mathrm{C}$, shaking) with the previously mentioned small molecules, or $\mathrm{KCl}$ (0.4 M final concentration) as a phopsho-Hog1 inducing control, or zymolyase $(0.26 \mathrm{U} / \mathrm{mL}$ final concentration) as a phospho-Slt2 inducing control (Boorsma et al. 2004). An untreated flask was kept aside as a negative control. One milliliter of culture from each flask/treatment group was harvested, spun down at 13,300 rpm for $2 \mathrm{~min}$. The supernatant was then discarded. Five-hundred microliters of media (YPD) and 0.7 $\mathrm{M} \mathrm{NaOH}$ was added to the tubes, and then vortexed. Samples were incubated at room temperature for $3 \mathrm{~min}$ and then spun down at $5000 \mathrm{rpm}$ for $2 \mathrm{~min}$. Afterward, the supernatant was carefully removed and $50 \mu \mathrm{L}$ of $2 \times$ SDS 
sample buffer (4\% SDS, 100 mM Tris pH 8.8, 100 mM DTT, 20\% glycerol and bromophenol blue) was added to the samples. Samples were mixed with gentle pipetting and then cell extracts were heated to $95^{\circ} \mathrm{C}$ in SDS sample buffer for 10 min before being run on a $10 \%$ SDS-PAGE gel (10\% acrylamide, $0.375 \mathrm{M}$ Tris$\mathrm{HCl} \mathrm{pH} \mathrm{8.8,10 \%} \mathrm{Glycerol,} \mathrm{0.1 \%} \mathrm{SDS,} \mathrm{0.1 \%} \mathrm{APS} \mathrm{and} \mathrm{TEMED).}$ Samples were transferred to a nitrocellulose membrane and detected using Hog1 (D-3) (Santa Cruz Biotechnology [sc-165978], Phospho-p38 [Hog1] MAPK [Cell Signaling Technology, 9211S]), or Phospho p44/42 (SIt2) MAPK (D13.14.4E; Cell Signaling Technology - 4370S) antibodies. GFP (Abcam, ab290) and GAPDH (Thermofisher Scientific, MA5-15738) antibodies were used as loading controls for Slt2 westerns. LiCOR secondary antibodies (IRDye 800CW Goat anti-Mouse IgG and IRDye 800CW Goat anti-Rabbit $\lg$ ) were used for final imaging. A precision plus dual color protein marker (Page Ruler Pre-stained Protein Ladder, Fisher Scientific- 26617) was used for band size estimates.

\section{Microscopy}

Five milliliters of cultures were grown in $50 \mathrm{~mL}$ conical flasks shaking at $30^{\circ} \mathrm{C}$ until midlog phase $\left(\mathrm{OD}_{600} 0.4-0.6\right)$ and treated with small molecules as described above. Glucose deprived yeast were washed twice in SD media lacking glucose. Cultures were placed back at $30^{\circ} \mathrm{C}$ to shake for $7 \mathrm{~min}$. Next, $300 \mu \mathrm{L}$ of culture was added onto an eight well Ibidi chamber slide (Ibidi 80821) treated with Concanavalin A (Cal Biochem - D00157580) to facilitate yeast adhesion, and left at room temperature for $3 \mathrm{~min}$. Culture media in wells was gently aspirated to remove unbound yeast cells and replaced with $150 \mu \mathrm{L}$ of identical culture media ( \pm small molecule, \pm glucose). Cells were then imaged on a DeltaVision Elite system as previously described (Buchan et al. 2010). A total of $3.2 \mu \mathrm{m} Z$ Z-stacks were collected, and Dot6-GFP, Sfp1-GFP, and P-body dynamics were quantified using Fiji (see Supplemental Table 2; Schindelin et al. 2012). Significance was assessed by One-way ANOVA with Dunnett's post-hoc test to assess sample variation relative to control cells.

\section{SUPPLEMENTAL MATERIAL}

Supplemental material is available for this article.

\section{ACKNOWLEDGMENTS}

This work was funded in part by a grant to J.R.B. from the National Institute of General Medical Sciences (NIGMS, R01GM1145664), and a T32 training grant (5T32GM008659-18) awarded to the MCB department at the University of Arizona.

Received August 16, 2019; accepted October 4, 2019.

\section{REFERENCES}

Albig AR, Decker CJ. 2001. The target of rapamycin signaling pathway regulates mRNA turnover in the yeast Saccharomyces cerevisiae. Mol Biol Cell 12: 3428-3438. doi:10.1091/mbc.12.11.3428

Banerjee D, Bloom ALM, Panepinto JC. 2016. Opposing PKA and Hog1 signals control the post-transcriptional response to glucose availability in Cryptococcus neoformans. Mol Microbiol 102: 306320. doi:10.1111/mmi.13461

Barbet NC, Schneider U, Helliwell SB, Stansfield I, Tuite MF, Hall MN. 1996. TOR controls translation initiation and early $\mathrm{G} 1$ progression in yeast. Mol Biol Cell 7: 25-42. doi:10.1091/mbc.7.1.25

Boeckstaens M, Merhi A, Llinares E, Van Vooren P, Springael J-Y, Wintjens R, Marini AM. 2015. Identification of a novel regulatory mechanism of nutrient transport controlled by TORC1-Npr1Amu1/Par32. PLoS Genet 11: e1005382. doi:10.1371/journal .pgen.1005382

Boorsma A, de Nobel $H$, ter Riet B, Bargmann B, Brul S, Hellingwerf KJ, Klis FM. 2004. Characterization of the transcriptional response to cell wall stress in Saccharomyces cerevisiae. Yeast 21: 413-427. doi:10.1002/yea.1109

Brengues M, Teixeira D, Parker R. 2005. Movement of eukaryotic mRNAs between polysomes and cytoplasmic processing bodies. Science 310: 486-489. doi:10.1126/science.1115791

Brewster JL, Gustin MC. 2014. Hog1: 20 years of discovery and impact. Sci Signal 7: re7. doi:10.1126/scisignal.2005458

Buchan JR. 2014. mRNP granules. Assembly, function, and connections with disease. RNA Biol 11: 1019-1030. doi:10.4161/ 15476286.2014.972208

Buchan JR, Nissan T, Parker R. 2010. Analyzing P-bodies and stress granules in Saccharomyces cerevisiae. Methods Enzymol 470: 619-640. doi:10.1016/S0076-6879(10)70025-2

Burger K, Mühl B, Kellner M, Rohrmoser M, Gruber-Eber A, Windhager L, Friedel CC, Dölken L, Eick D. 2013. 4-thiouridine inhibits rRNA synthesis and causes a nucleolar stress response. RNA Biol 10: 1623-1630. doi:10.4161/rna.26214

Chan LY, Mugler CF, Heinrich S, Vallotton P, Weis K. 2018. Non-invasive measurement of mRNA decay reveals translation initiation as the major determinant of mRNA stability. Elife 7: e32536. doi:10 $.7554 /$ eLife. 32536

Coller J. 2008. Methods to determine mRNA half-life in Saccharomyces cerevisiae. Methods Enzymol 448: 267-84. doi:10.1016/S0076-6879(08)02614-1

Fan J, Yang X, Wang W, Wood WH, Becker KG, Gorospe M, Gorospe M. 2002. Global analysis of stress-regulated mRNA turnover by using cDNA arrays. Proc Natl Acad Sci 99: 10611-10616. doi:10.1073/pnas.162212399

García R, Pulido V, Orellana-Muñoz S, Nombela C, Vázquez de Aldana CR, Rodríguez-Peña JM, Arroyo J. 2019. Signalling through the yeast MAPK cell wall integrity pathway controls $\mathrm{P}_{-}$ body assembly upon cell wall stress. Sci Rep 9: 3186. doi:10 .1038/s41598-019-40112-9

García-Martínez J, Aranda A, Pérez-Ortín JE. 2004. Genomic run-on evaluates transcription rates for all yeast genes and identifies gene regulatory mechanisms. Mol Cell 15: 303-313. doi:10 .1016/j.molcel.2004.06.004

Gietz RD, Woods RA. 2006. Yeast transformation by the LiAc/SS carrier DNA/PEG method. Methods Mol Biol 313: 107-120. doi:10 .1385/1-59259-958-3:107

Grigull J, Mnaimneh S, Pootoolal J, Robinson MD, Hughes TR. 2004. Genome-wide analysis of mRNA stability using transcription inhibitors and microarrays reveals posttranscriptional control of ribosome biogenesis factors. Mol Cell Biol 24: 5534-5547. doi:10 .1128/MCB.24.12.5534-5547.2004

Heinisch JJ, Rodicio R. 2018. Protein kinase C in fungi-more than just cell wall integrity. FEMS Microbiol Rev 42: fux051. doi:10.1093/ femsre/fux051

Hu G, McQuiston T, Bernard A, Park Y-D, Qiu J, Vural A, Zhang N, Waterman SR, Blewett NH, Myers TG, et al. 2015. A conserved mechanism of TOR-dependent RCK-mediated mRNA degradation regulates autophagy. Nat Cell Biol 17: 930-942. doi:10 $.1038 / \mathrm{ncb} 3189$ 
Huber A, French SL, Tekotte H, Yerlikaya S, Stahl M, Perepelkina MP, Tyers M, Rougemont J, Beyer AL, Loewith R. 2011. Sch9 regulates ribosome biogenesis via Stb3, Dot6 and Tod6 and the histone deacetylase complex RPD3L. EMBO J 30: 3052-3064. doi:10 .1038/emboj.2011.221

Hughes TR, Marton MJ, Jones AR, Roberts CJ, Stoughton R, Armour CD, Bennett HA, Coffey E, Dai H, He YD, et al. 2000. Functional discovery via a compendium of expression profiles. Cell 102: 109-126. doi:10.1016/S0092-8674(00)00015-5

Hughes Hallett JE, Luo X, Capaldi AP. 2014. State transitions in the TORC1 signaling pathway and information processing in Saccharomyces cerevisiae. Genetics 198: 773-786. doi:10.1534/ genetics.114.168369

Jain S, Parker R. 2013. The discovery and analysis of P bodies. Adv Exp Med Biol 768: 23-43. doi:10.1007/978-1-4614-5107-5_3

Jorgensen P, Rupes I, Sharom JR, Schneper L, Broach JR, Tyers M. 2004. A dynamic transcriptional network communicates growth potential to ribosome synthesis and critical cell size. Genes Dev 18: 2491-2505. doi:10.1101/gad.1228804

Lempiäinen H, Uotila A, Urban J, Dohnal I, Ammerer G, Loewith R, Shore D. 2009. Sfp1 interaction with TORC1 and Mrs6 reveals feedback regulation on TOR signaling. Mol Cell 33: 704-716. doi:10.1016/j.molcel.2009.01.034

Lippman SI, Broach JR. 2009. Protein kinase A and TORC1 activate genes for ribosomal biogenesis by inactivating repressors encoded by Dot6 and its homolog Tod6. Proc Natl Acad Sci 106: 1992819933. doi:10.1073/pnas.0907027106

Loewith R, Hall MN. 2011. Target of rapamycin (TOR) in nutrient signaling and growth control. Genetics 189: 1177-1201. doi:10 .1534 /genetics.111.133363

Luo G, Costanzo M, Boone C, Dickson RC. 2011. Nutrients and the Pkh1/2 and Pkc1 protein kinases control mRNA decay and Pbody assembly in yeast. J Biol Chem 286: 8759-8770. doi:10 $.1074 / j b c . M 110.196030$

Marion RM, Regev A, Segal E, Barash Y, Koller D, Friedman N, O'Shea EK. 2004. Sfp1 is a stress- and nutrient-sensitive regulator of ribosomal protein gene expression. Proc Natl Acad Sci 101: 14315-14322. doi:10.1073/pnas.0405353101

Mnaimneh S, Davierwala AP, Haynes J, Moffat J, Peng W-T, Zhang W, Yang X, Pootoolal J, Chua G, Lopez A, et al. 2004. Exploration of essential gene functions via titratable promoter alleles. Cell 118: 31-44. doi:10.1016/j.cell.2004.06.013

Molin C, Jauhiainen A, Warringer J, Nerman O, Sunnerhagen P. 2009. mRNA stability changes precede changes in steady-state mRNA amounts during hyperosmotic stress. RNA 15: 600-614. doi:10 $.1261 /$ rna.1403509

Morano KA, Grant CM, Moye-Rowley WS. 2012. The response to heat shock and oxidative stress in Saccharomyces cerevisiae. Genetics 190: 1157-1195. doi:10.1534/genetics.111.128033
Munchel SE, Shultzaberger RK, Takizawa N, Weis K. 2011. Dynamic profiling of mRNA turnover reveals gene-specific and systemwide regulation of mRNA decay. Mol Biol Cell 22: 2787-2795. doi:10.1091/mbc.e11-01-0028

Nonet M, Scafe C, Sexton J, Young R. 1987. Eucaryotic RNA polymerase conditional mutant that rapidly ceases mRNA synthesis. Mol Cell Biol 7: 1602-1611. doi:10.1128/MCB.7.5.1602

Parker R, Herrick D, Peltz SW, Jacobson A. 1991. Measurement of mRNA decay rates in Saccharomyces cerevisiae. Methods Enzymol 194: 415-423. doi:10.1016/0076-6879(91)94032-8

Pérez-Ortín JE, Alepuz PM, Moreno J. 2007. Genomics and gene transcription kinetics in yeast. Trends Genet 23: 250-257. doi:10 .1016/j.tig.2007.03.006

Pérez-Ortín JE, Alepuz P, Chávez S, Choder M. 2013. Eukaryotic mRNA decay: methodologies, pathways, and links to other stages of gene expression. J Mol Biol 425: 3750-3775. doi:10.1016/j.jmb .2013 .02 .029

Romero-Santacreu L, Moreno J, Pérez-Ortín JE, Alepuz P. 2009. Specific and global regulation of mRNA stability during osmotic stress in Saccharomyces cerevisiae. RNA 15: 1110-1120. doi:10 .1261/rna.1435709

Schindelin J, Arganda-Carreras I, Frise E, Kaynig V, Longair M, Pietzsch T, Preibisch S, Rueden C, Saalfeld S, Schmid B, et al. 2012. Fiji: an open-source platform for biological-image analysis. Nat Methods 9: 676-682. doi:10.1038/nmeth.2019

Schoenberg DR, Maquat LE. 2012. Regulation of cytoplasmic mRNA decay. Nat Rev Genet 13: 246-259. doi:10.1038/nrg3160

Sun M, Schwalb B, Schulz D, Pirkl N, Etzold S, Larivière L, Maier KC, Seizl M, Tresch A, Cramer P. 2012. Comparative dynamic transcriptome analysis (cDTA) reveals mutual feedback between mRNA synthesis and degradation. Genome Res 22: 1350-1359. doi:10 $.1101 /$ gr.130161.111

Talarek N, Bontron S, De Virgilio C. 2013. Quantification of mRNA stability of stress-responsive yeast genes following conditional excision of open reading frames. RNA Biol 10: 1299-1308. doi:10 $.4161 /$ rna. 25355

Thomas G, Hall MN. 1997. TOR signalling and control of cell growth. Curr Opin Cell Biol 9: 782-787. doi:10.1016/S0955-0674(97) 80078-6

Urban J, Soulard A, Huber A, Lippman S, Mukhopadhyay D, Deloche O, Wanke V, Anrather D, Ammerer G, Riezman H, et al. 2007. Sch9 is a major target of TORC1 in Saccharomyces cerevisiae. Mol Cell 26: 663-674. doi:10.1016/j.molcel.2007.04.020

Wada T, Becskei A, Wada T, Becskei A. 2017. Impact of methods on the measurement of mRNA turnover. Int J Mol Sci 18: 2723. doi:10.3390/ijms18122723

Yoon J-H, Choi E-J, Parker R. 2010. Dcp2 phosphorylation by Ste20 modulates stress granule assembly and mRNA decay in Saccharomyces cerevisiae. J Cell Biol 189: 813-827. doi:10 $.1083 / j c b .200912019$ 

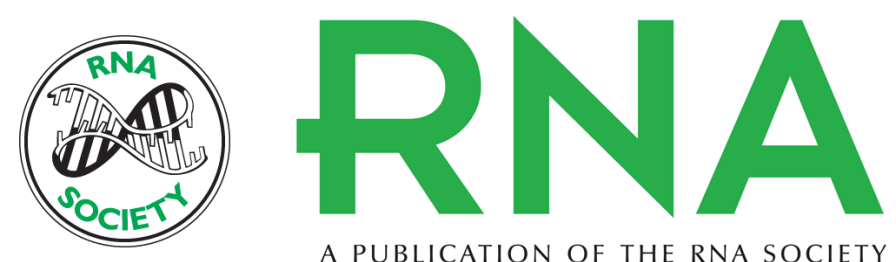

A PUBLICATION OF THE RNA SOCIETY

\section{Alterations of signaling pathways in response to chemical perturbations used to measure mRNA decay rates in yeast}

Nichole Eshleman, Xiangxia Luo, Andrew Capaldi, et al.

RNA 2020 26: 10-18 originally published online October 10, 2019

Access the most recent version at doi:10.1261/rna.072892.119

\section{Supplemental http://rnajournal.cshlp.org/content/suppl/2019/10/10/rna.072892.119.DC1 Material}

References This article cites 46 articles, 20 of which can be accessed free at: http://rnajournal.cshlp.org/content/26/1/10.full.html\#ref-list-1

Creative This article is distributed exclusively by the RNA Society for the first 12 months after the Commons License full-issue publication date (see http://rnajournal.cshlp.org/site/misc/terms.xhtml). After 12 months, it is available under a Creative Commons License (Attribution-NonCommercial 4.0 International), as described at http://creativecommons.org/licenses/by-nc/4.0/.
Email Alerting Receive free email alerts when new articles cite this article - sign up in the box at the Service top right corner of the article or click here.

\section{IIII!" Providing Precise Solutions tor your research.}

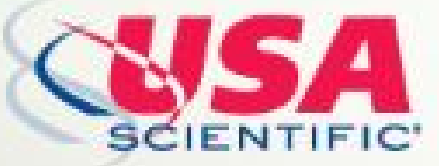

To subscribe to $R N A$ go to:

http://rnajournal.cshlp.org/subscriptions

(C) 2020 Eshleman et al.; Published by Cold Spring Harbor Laboratory Press for the RNA Society 